Supporting Information

\title{
Availability of Environmental Iron Influences the Performance of Biological Adhesives Produced by Blue Mussels
}

\author{
Natalie A. Hamada, Christopher Gilpin, and Jonathan J. Wilker
}

\section{Materials and Methods}

Figure S1 Work of detachment data

Figure S2 Analysis of failure modes

Table S1 Artificial seawater conditions

Table S2 Adhesive properties

Table S3 Statistical analysis

Table S4 Condition index health and sizes of animals 


\section{Materials and Methods}

No unexpected or unusually high safety hazards were encountered.

Aquarium System.

Mussels were obtained from Jess's Market in Rockland, Maine and housed in a 300 gallon aquarium system. Prior to the experiments of this study, animals were fed every 2-3 days with Phytofeast concentrated plankton. The system was held at a constant $4{ }^{\circ} \mathrm{C}$, contained a surge system to mimic shore breaks, and a timed light system to provide day/night cycles of Maine in February. Weekly $1 / 3$ water changes were made to maintain low dissolved nitrogen levels. Details of this aquarium system were reported previously. ${ }^{1}$

\section{Preparation of Artificial Seawater.}

Artificial seawater was made from Aquacraft Marine Environment Salt. The salt mixture was dissolved in deionized water to a final salinity of 28-30 ppt measured by a refractometer. The freshly prepared saltwater was aerated, aged, and chilled for at least 7 days prior to use. Doing so ensured conversion of nutrients to forms found in natural seawater. ${ }^{2}$ See Table S1 for measured seawater nutrient levels.

Preparation of Iron Deficient Conditions.

Trace metal clean techniques were used throughout the preparation of iron deficient seawater. ${ }^{3,4}$ Tanks were made from high density polyethylene (HDPE) fitted with polypropylene (PP) pressure relief valves. Tubing used was of perfluoroalkoxy alkane (PFA) purchased from

Savillex. Preparation of iron deficient conditions were carried out using a homemade in line 
system consisting of a peristaltic pump, polypropylene in line membrane holders, Kontes Flex chromatography columns, and fluorinated ethylene propylene (FEP) tubing. Seven day aged artificial seawater was filtered twice through $0.2 \mu \mathrm{m}$ Nuclepore membranes and this filtrate was passed through a Chelex 100 ion exchange resin column at a rate of $<1 \mathrm{~mL} / \mathrm{min}$. Chelex 100 resin was recharged with $1 \mathrm{M} \mathrm{HCl}, 18.2 \mathrm{M} \Omega \mathrm{cm}$ deionized water rinses, adjusted to $\mathrm{pH}=5.5$ using $0.5 \mathrm{M}$ sodium acetate buffer, and excess salt was rinsed away with deionized water. The eluted seawater was collected in an enclosed HDPE $4 \mathrm{~L}$ bottle with HEPA ventilation. The $\mathrm{pH}$ of this seawater was adjusted to $\mathrm{pH}=10$ using trace metal free $6 \mathrm{M} \mathrm{NaOH}$. The $\mathrm{pH}$ was then decreased to $\mathrm{pH}=8$ upon aeration with HEPA filtered air and cooling to $4{ }^{\circ} \mathrm{C}$.

Experiments with animals were carried out in acid washed polypropylene tanks and aerated with in line HEPA filtered ambient air. These tanks with mussels were maintained in a $4{ }^{\circ} \mathrm{C}$ glass door refrigerator. Iron deficient seawater was previously transferred from the HDPE reservoir bottle to polypropylene tanks while working inside a HEPA filtered laminar flow hood.

\section{Preparation of Iron Loaded Seawater.}

Spherical iron powder, $<10 \mu \mathrm{m}$, was purchased from Sigma (CAS \# 7439-89-6). Iron loaded seawater was prepared from aged Aquacraft seawater and filtered through a $0.4 \mu \mathrm{m}$ Nuclepore membrane housed within an in line polypropylene filter holder. Seawater was filtered under positive pressure using a peristaltic pump and collected into polypropylene tanks to a final volume of $3 \mathrm{~L}$. Experimental waters were aerated with ambient, unfiltered air using an aquarium air pump and cooled to $4{ }^{\circ} \mathrm{C}$ prior to addition of mussels. Animals were placed atop aluminum substrates using rubber bands and put into tanks. Upon visual confirmation of their exposed 
siphons, an indication of active filtering, respective amounts of iron powder were added to the tanks.

\section{Adhesion Data Collection.}

Adhesive threads were severed from the animals on day 3. Digital images were taken of the plaques using a DSLR camera affixed with a $30 \mathrm{~mm}$ extension tube. Care was taken to keep adhesive samples hydrated after cutting from the mussels. The threads, still attached to substrates, were held in a water tank until tested for adhesion. At most, there were two hours between cutting from the animals and adhesion quantification. Images were processed to measure each plaque area using imaging processing software, ImageJ.

Threads were clamped entirely and oriented orthogonal to the substrate plane. An Instron 5544 materials testing system was used to pull an upward force on the adhesive at a rate of $2 \mathrm{~mm} / \mathrm{min}$. Forces $(\mathrm{N})$ were recorded until material failure, yielding a force-extension curve. Failure modes were recorded for each plaque. Adhesion $(\mathrm{kPa})$ was calculated as the maximum force of detachment $\left(\mathrm{F}_{\max }\right)$ per unit area. The integral of the force-extension curves per unit area were calculated for work of detachment $\left(\mathrm{J} / \mathrm{m}^{2}\right)$. This method of measuring mussel adhesion has been used and reported previously. ${ }^{1,5}$

\section{Quantification of Particulate Iron in Seawater.}

Absorbance spectroscopy was used to determine particulate iron concentrations for each seawater condition. ${ }^{3,6,7}$ Trace metal clean techniques were used throughout the process. Labware consisted of either high density polypropylene (HDPE), low density polypropylene (LDPE), or perfluoroalkoxy alkane (PFA) materials. All labware was previously cleaned using an Alconox soak (24 h), 18.2 M $\Omega \mathrm{cm}$ deionized water rinses, and a nitric acid soak (24 h). Acid 
cleaned materials were rinsed with $18.2 \mathrm{M} \Omega \mathrm{cm}$ deionized water and dried in a HEPA filtered laminar flow hood. All reagents used were of trace metal grade and solutions prepared using 18.2 $\mathrm{M} \Omega \mathrm{cm}$ deionized water in polypropylene volumetric flasks.

Particulate iron fractions were collected into $0.4 \mu \mathrm{m}$ Nuclepore membranes housed in Nalgene polycarbonate filter holders. The particulate samples containing membranes were digested in PFA bombs with a 4:1 nitric acid:30\% hydrogen peroxide solution. The mixture was filtered using acid cleaned $0.4 \mu \mathrm{m}$ polypropylene syringe filters and transferred to a PFA beaker. Samples were heated and concentrated to almost dryness. The transparent solution was allowed to cool and adjusted to $\mathrm{pH} 5.5$ with an acetate buffer. Ascorbic acid and Ferrozine solutions were added to the remaining concentrate, yielding a pink, Fe(II)-Ferrozine complex. The solution was made up to a final volume in polypropylene volumetric flasks with $18.2 \mathrm{M} \Omega \mathrm{cm}$ deionized water and absorbance measured at $\lambda=562 \mathrm{~nm}$ using a Cary 100 Bio UV-Vis spectrophotometer. Three standard curves was prepared and averaged to determine total particulate iron concentrations.

\section{Condition Index Health Measurements.}

After completion of adhesion experiments, animals were stored at $-80{ }^{\circ} \mathrm{C}$ until analysis. The length of the valves (i.e. shells) were recorded by measuring the longest distance between the posterior and anterior regions using a digital caliper. Frozen mussel samples were each placed in boiling deionized water for 2 minutes. The meat was separated from the shell using a scalpel. The meat and shells were dehydrated in an oven for $48 \mathrm{~h}$ at $60{ }^{\circ} \mathrm{C}$. Masses were then

measured to the nearest $0.0001 \mathrm{~g}$. Condition indices were calculated using the equation below. ${ }^{8,9}$ 
Averages were taken from at least 12 animals and are reported in Table S4 with errors of 95\% confidence intervals.

$$
\text { Condition index }=\frac{\text { mass of dried meat }}{\text { mass of dried shell }} \times 100
$$

\section{Preparation of Samples for Scanning Electron Microscopy.}

Mussels were previously exposed to a 10 day starvation period prior to sample collection. Animals were then placed into their respective waters and allowed to deposit plaques on acidwashed 10.2 x $10.2 \mathrm{~cm}$ Teflon substrates lined with 1 inch adhesive-backed Teflon bench protector tape so that samples could be easily excised and transferred for processing without direct handling of the plaque samples. Adhesive plaques were collected after 3 days. The Teflon surface protectors with samples were harvested and processed for microscopy, starting with overnight fixation in $4 \%$ glutaraldehyde-seawater solution at $4{ }^{\circ} \mathrm{C}$. After rinsing $3 \mathrm{X}$ with deionized water, samples were further fixated in $1 \%$ osmium tetroxide for $1 \mathrm{~h}$. These plaques were then rinsed $3 \mathrm{X}$ with deionized water after osmium fixation and slowly dehydrated with successive water:ethanol solutions $(1: 1,1: 2,1: 9,0: 1)$ followed by ethanol:hexamethyldisilazane (HMDS; 3:1, 1:1, 1:3, 0:1) solutions. After evaporation of remaining HMDS, adhesive plaques were easily removed from the Teflon substrates. The lower halves were bonded to aluminum substrates lined with carbon tape while the upper halves remained at an overhang. The aluminum-tape-plaque cluster was immersed in liquid nitrogen and the overhang fractured using tweezers, thereby revealing a cross section of the bulk plaque. The cross sections were coated with platinum for $60 \mathrm{~s}$ using a sputter coater and imaged with a Nova NanoSEM under high vacuum, an accelerating voltage of $5 \mathrm{kV}$, and either an Everhart Thornley detector or Throughthe-Lens detector (high magnification). 


\section{References}

(1) Burkett, J. R.; Wojtas, J. L.; Cloud, J. L.; Wilker, J. J. "A Method for Measuring the Adhesion Strength of Marine Mussels" J. Adhesion 2009, 85, 601-615.

(2) Kuma, K.; Nishioka, J.; Matsunaga, K. "Controls on Iron (III) Hydroxide Solubility in Seawater: The Influence of $\mathrm{pH}$ and Natural Organic Chelators" Limnol. Oceanogr. 1996, 41, 396-407.

(3) Bruland, K. W.; Rue, E. L. In The Biogeochemistry of Iron in Seawater; Turner, D. R., Hunter, K. A., Eds.; John Wiley and Sons: Hoboken, NJ, 2002, p 255-289.

(4) Achterberg, E. P.; Holland, T. W.; Bowie, A. R.; Fauzi, R.; Mantoura, C.; Worsfold, P. J. "Marine Biogeochemistry of Iron" Anal. Chim. Acta 2001, 442, 1-14.

(5) Waite, J. H. "The Phylogeny and Chemical Diversity of Quinone-Tanned Glues and Varnishes" Comp. Biochem. Physiol. 1990, 97B, 19-29.

(6) Stookey, L. L. "Ferrozine- A New Spectrophotometric Reagent for Iron" Anal. Chem. 1970, 42, 779-781.

(7) Lin, J.; Kester, D. R. "The Kinetics of Fe(II) Complexation by Ferrozimne in Seawater" Mar. Chem. 1992, 38, 283-301.

(8) Baird, R. H. "Measurement of Condition in Mussels and Oysters" J. Conseil. Perm. Explor. Mer. 1957, 23, 249-257.

(9) Davenport, J.; Chen, X. "A Comparison of Methods for the Assessment of Condition in the Mussel (Mytilus edulis L.)" J. Molluscan Stud. 1987, 53, 293-297. 

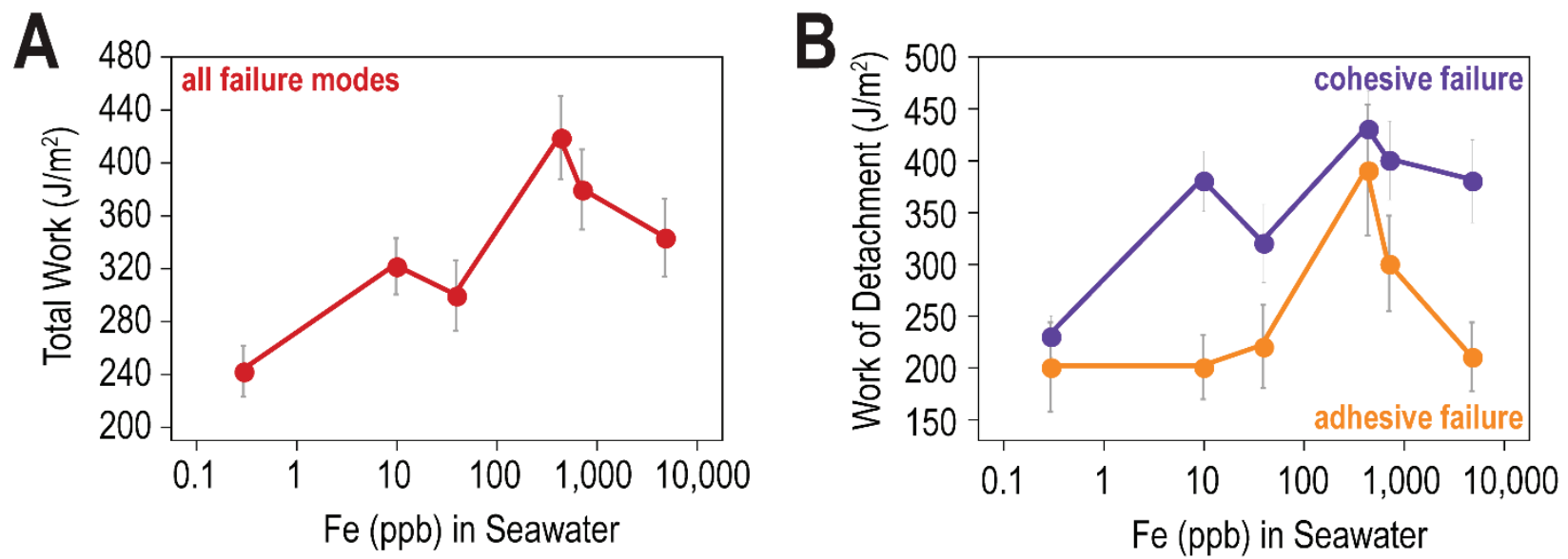

Figure S1.

Work of detachment data. (A) Total work of detachment including all failure modes. (B) Work of detachment resulting from cohesive failure (orange) and adhesive failure (purple). Error bars depict $95 \%$ confidence intervals. 


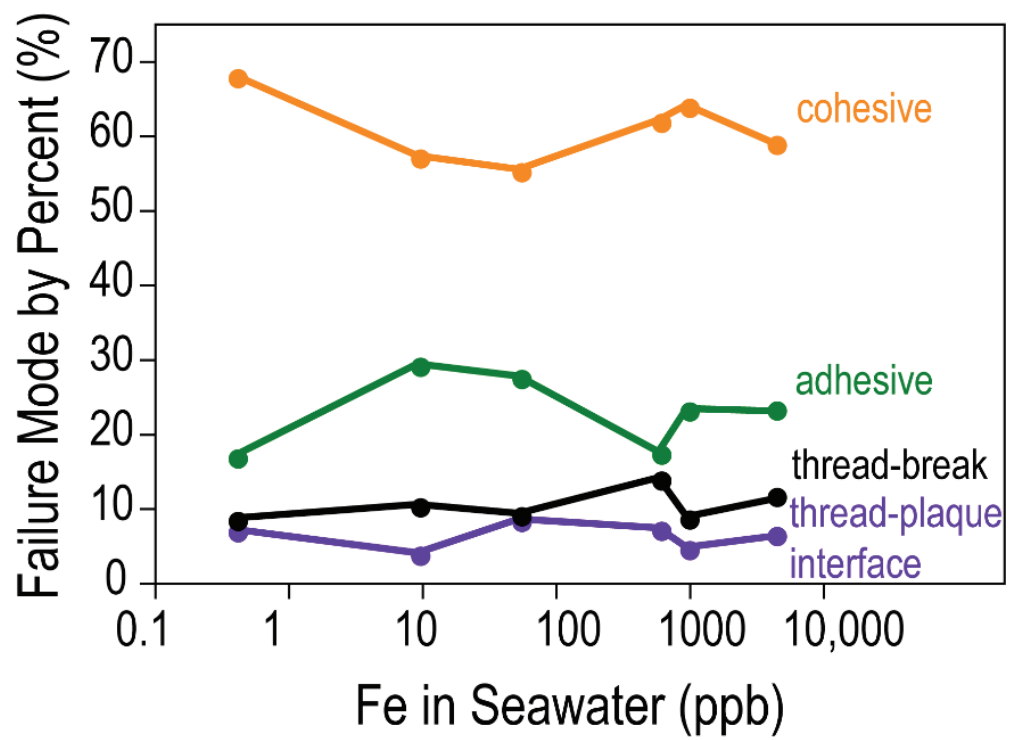

Figure S2.

Analysis of adhesive failure observed when seawater iron content was varied. Cohesive failure (orange), adhesive failure (green), thread break (black), and thread-plaque interface (purple) are shown separately. 


\section{Table S1.}

Control artificial seawater conditions filtered though $0.4 \mu \mathrm{m}$ membranes. Parameters measured were determined using a LaMotte Saltwater Aquaculture Outfit Model AQ-4.

\begin{tabular}{lc}
\hline Test Parameter & Reported values \\
\hline Salinity & $28-30 \mathrm{ppt}$ \\
$\mathrm{pH}$ & $8.1-8.2$ \\
Total ammonia-nitrogen & $0.05 \mathrm{ppm}$ \\
Nitrite-nitrogen; $\mathrm{NO}_{2}-\mathrm{N}$ & $0.05 \mathrm{ppm}$ \\
Nitrate-nitrogen; $\mathrm{NO}_{3}-\mathrm{N}$ & $0.05 \mathrm{ppm}$ \\
Alkalinity & $14.5 \mathrm{ppm}$ \\
Dissolved oxygen, $\mathrm{O}_{2}$ & $9.6 \mathrm{ppm}$ \\
\hline
\end{tabular}




\section{Table S2.}

Adhesive properties of mussels grown in waters of differing iron concentrations. A control was performed with every experimental run, resulting in a relatively large sample population for the 10.4 ppb samples.

\begin{tabular}{|c|c|c|c|c|c|c|c|}
\hline $\begin{array}{l}\text { Measured } \\
\text { seawater } \\
\text { Fe (ppb) }\end{array}$ & $\begin{array}{l}\text { Intended } \\
\text { seawater } \\
\text { Fe (ppb) }\end{array}$ & $\begin{array}{l}\text { Number } \\
\text { of } \\
\text { plaques }\end{array}$ & $\begin{array}{l}\text { Avg. } \\
\text { No. } \\
\text { plaques } \\
\text { per } \\
\text { animal }\end{array}$ & Force $(\mathrm{N})$ & $\begin{array}{l}\text { Plaque area } \\
\left(\mathrm{mm}^{2}\right)\end{array}$ & $\begin{array}{l}\text { Total } \\
\text { work } \\
\left(\mathrm{J} / \mathrm{m}^{2}\right)\end{array}$ & $\begin{array}{l}\text { Adhesi } \\
\text { on } \\
(\mathrm{kPa})\end{array}$ \\
\hline 0.3 & - & 201 & 6.7 & $0.44 \pm 0.02 *$ & $5.15 \pm 0.20^{*}$ & $240 \pm 20$ & $89 \pm 5$ \\
\hline 10.4 & - & 433 & 6.0 & $0.51 \pm 0.02$ & $4.53 \pm 0.11^{*}$ & $320 \pm 20$ & $117 \pm 4$ \\
\hline 40.0 & - & 288 & 6.8 & $0.54 \pm 0.03$ & $4.53 \pm 0.12$ & $300 \pm 30$ & $124 \pm 6$ \\
\hline 444 & 1,000 & 225 & 6.3 & $0.53 \pm 0.03 *$ & $4.50 \pm 0.18$ & $420 \pm 30$ & $125 \pm 6$ \\
\hline 720 & 2,500 & 290 & 8.1 & $0.50 \pm 0.02$ & $4.05 \pm 0.12 *$ & $380 \pm 30$ & $129 \pm 7$ \\
\hline 4821 & 10,000 & 233 & 7.8 & $0.48 \pm 0.02 *$ & $4.63 \pm 0.20$ & $340 \pm 30$ & $109 \pm 5$ \\
\hline
\end{tabular}

*indicates statistically significant adjacent pairs of datasets. 


\section{Table S3.}

Statistical analysis of adhesive measurements for data in Figure 2A, shown here again. ANOVA was used to assess equality of variances within datasets. The null hypothesis was rejected at a confidence level of $90 \%(\mathrm{p}<0.05)$, meaning that we can assume equal variances across datasets when the calculated statistic is greater than $\mathrm{p}$. ANOVA showed inhomogenous variances within the datasets, thus a Games-Howell post-hoc test was used to examine significant differences between datasets.

\begin{tabular}{lcl}
\hline Group & Seawater Fe $(\mathrm{ppb})$ & $\mathrm{p}$ value \\
\hline A:B & $0.3: 10.4$ & $<0.001$ \\
B:C & $10.4: 720$ & 0.022 \\
C:D & $720: 4821$ & $<0.001$ \\
A:D & $0.3: 4821$ & $<0.001$ \\
\hline
\end{tabular}

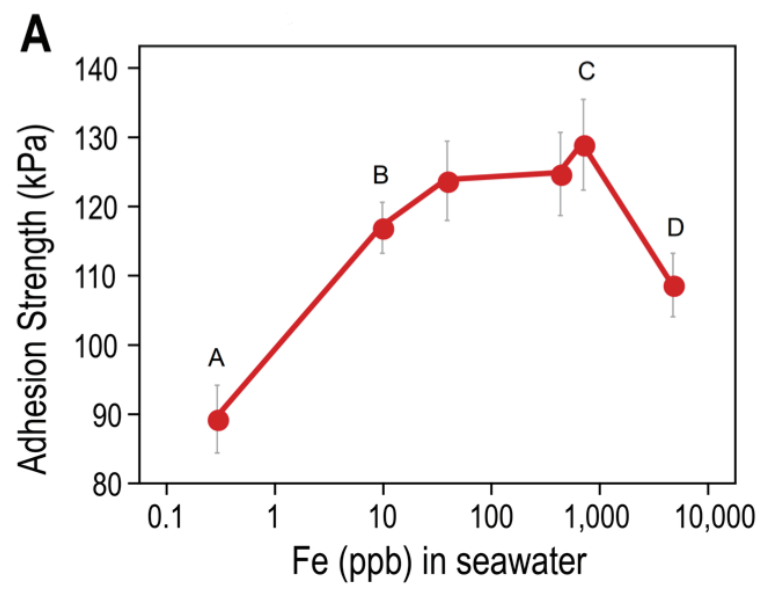


For adhesion force:

\begin{tabular}{lcl}
\hline Group & Seawater Fe $(\mathrm{ppb})$ & $\mathrm{p}$ value \\
\hline & & \\
A:B & $0.3: 10.4$ & $<0.001$ \\
B:C & $10.4: 720$ & 0.015 \\
A:C & $0.3: 4821$ & 0.037 \\
\hline
\end{tabular}

Figure 2B.

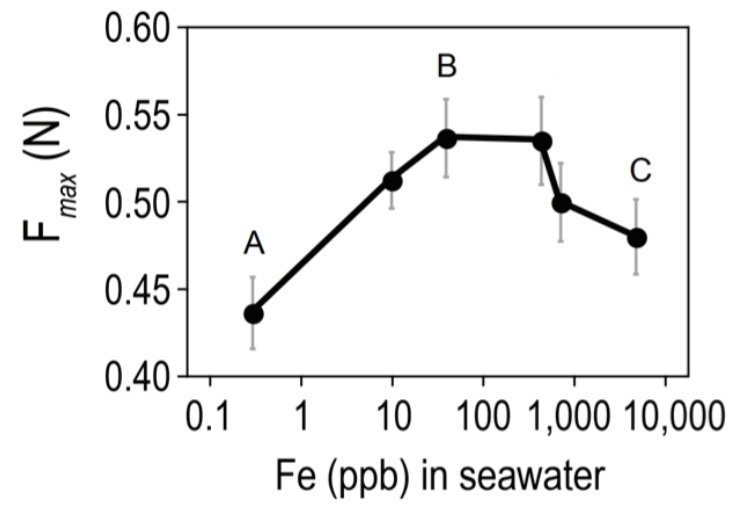

For adhesion area:

\begin{tabular}{lcc}
\hline Group & Seawater Fe $(\mathrm{ppb})$ & $\mathrm{p}$ value \\
\hline & & \\
$\mathrm{A}: \mathrm{B}$ & $0.3: 10.4$ & $<0.001$ \\
$\mathrm{~B}: \mathrm{C}$ & $10.4: 720$ & $<0.001$ \\
$\mathrm{~A}: \mathrm{C}$ & $0.3: 720$ & $<0.001$ \\
\hline
\end{tabular}

Figure 2C.

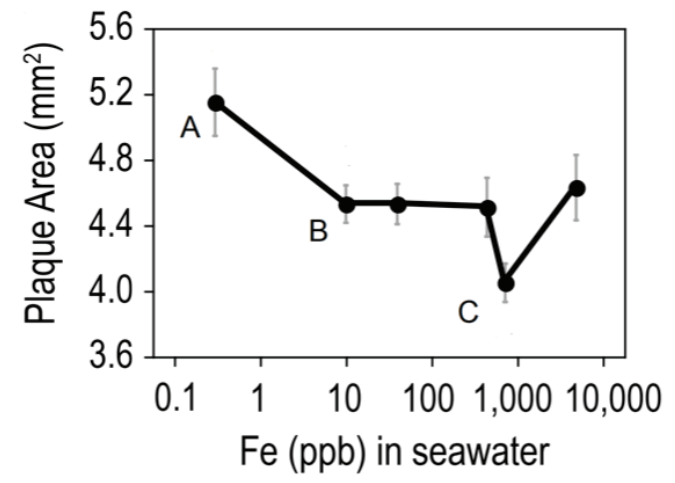




\section{Table S4.}

Condition index health and size of animals. The condition indices were determined by the weight ratios of dehydrated soft tissue to dehydrated shell. Lower values indicate wasting and poor health. Errors reported are 95\% confidence intervals. All animals had a shell length in the 55-75 mm range. Averages with 95\% confidence intervals are shown.

\begin{tabular}{lcc}
\hline Seawater Fe $(\mathrm{ppb})$ & Condition Index & Shell Length $(\mathrm{mm})$ \\
\hline 0.3 & $21 \pm 3$ & $67 \pm 1$ \\
10 & $14 \pm 2$ & $66 \pm 1$ \\
40 & $16 \pm 2$ & $68 \pm 1$ \\
444 & $13 \pm 2$ & $65 \pm 1$ \\
720 & $12 \pm 2$ & $68 \pm 2$ \\
4821 & $13 \pm 2$ & $67 \pm 2$ \\
\hline
\end{tabular}

